\title{
SCIENCE
}

NEW YORK, JULY 15, 1892.

\section{THE CHEMISTRY OF SOILS.'}

BY PROFESSOR R. ELLSWORTH CALL.

A somewhat extended experience in the chemical analysis of soils with a view to their agricultural value has led to certain conclusions which may not be altogether devoid of value to the readers of Science. Especially may this be true since there is of ten an entirely erroneous opinion among those most concerned respecting the useful deductions which may be made from a complete chemical analysis of a soil. Usually it happens that if only the presence of certain desirable substances be shown, then the value of the soil for the production of this or that crop is assumed to be definitely settled. Nothing could, in general, be farther from the truth. Of course, something definite may be said of such soils as those in which both sand and clays, or either, predominate, but the conclusions in these cases are based on the physical characteristics of the soils rather than on their chemistry. Indeed, it is usual to classify soils in two general categories, the classification being based, on the one hand, on the method of soil-formation, and, on the other hand, on its physical characteristics. The soils of Towa belong, in the main, to that class which is based on the method of formation, and are composed chiefly of transported or drift materials. It is, however, true that the Iowa soils, though glacial, owe much to the physical characters of the rocks which they represent as disintegrated and far-travelled débris. The sands and clays are all transported materials, most of them from points many miles to the north of the prairie regions which they now cover. It is, moreover, clear that no degree of coarseness or of fineness, which may result from the methods of origination of any soil, constitutes in itself sufficient ground for saying this soil is fertile or that soil is unsuitable for plant growth. Recourse must be had to the ultimate composition of the sample, and right here enters an element of error against which, popularly, it is difficult to guard.

The physical sharacter of a soil or marl must be considered when studied chemically. The finer the condition of the sample, in nature, the more readily are induced those changes in its chemistry which result from atmospheric influences. That is to say, when coarse and fine soils are treated alike mechanically by the plow, the one may become mellow and well mixed, while the other is broken without being well mixed or turned. Now, the chemical processes which occur are most active and most complete in soils that are fine in texture. It follows, therefore, that a stiff, clayey soil may contain all the essential elements of the food of any plant, but be in such condition physically as to render the chemical processes difficult of operation. And, on the other hand, such a soil may be sufficiently fine, but the well-known tendency to "cake" or harden on drying or exposure would render it valueless agriculturally, no matter bow finely comwinuted its materials may be.

1 Extracted from the Monthly Review Iowa Weather and Crop Service, Vol. III., No. 5, May, 1892.
Clayey soils, again, do not permit that free, subsoil cirm culation of water so necessary to growing crops. Circulation there is, but it is limited at best; open, porous soils admit free, underground water-flows, but such soils soon dry. They lose large quantities of water through evaporation, due to the rather free circulation of air in the upper portions of the cultivated areas.

Color, too, has little to do with deciding finally whether a soil will be fertile. Usually all earths which are dark. colored or black - a condition largely due to the amount of carbonaceous material derived from decayed vegetation are considered fertile. It is true that common consent places all such samples among the fertile soils, but it by no means follows as a necessary deduction. So, too, that light drab or ashy-colored soils lack the elements of fertility is a notion which observation and experiment alike negative. The most fertile of Iowa soils is the loess, a peculiar and very fine marl covering many hundred square miles along the Mississippi and Missouri rivers, as well as the higher lands along the Des Moines. It is a soil the color of which would condemn it for agricultural purposes, but it is one which is of exceptional value for all sorts of cereals, and is peculiarly adapted to the growth of fruit. It is finer in texture than is any other soil in the State. What, then, constitutes its peculiar feature, rendering it so valuable? The answer to the query lies almost solely in its physical condition, which is of a fineness equalling that of any clay. This fine condition renders it admirably suited to the action of native chemical agents. These are the real soil-makers. Soils that plants may use must be soluble, and one of the essentials to complete solubility is fineness of the constituent particles. A certain and definite relation to moisture must be estab-lished and maintained, a condition which is practically reached by under-draining soils of a clayey nature. Too much water will compel adhesion of the smaller particles, and the product thus formed be eventually coarse and lumpy. Such a soil may be very fertile, but is not arable. This is the condition of most of the bottom lands of eastern Arkansas, the soils of which region are deficient in lime alone of all the ingredients which plants require. They are "wet and cold," and cannot be under-drained. Few soils of this nature occur in. Iowa.

To make a long story short, chemical analysis of any given soil will determine its probable agricultural value only within very wide limits, and for reasons which appear below. It may be said, at this time, that such an analysis may determine one of two things, $(\alpha)$ the presence or absence of constituents which the plant must have, or $(b)$ the presence of some substance which will affect injuriously a growing plant. The chemical laboratory will never supplant the province of carefully conducted experimental agriculture. But it may become a most valuable adjunct to the operations of the farm. The principles which underlie agricultural chemistry need only to be understood to be appreciated by those who have the manual labor of the farm to perform.

Aside from these general considerations there remain yet others to which it will be well to advert. 
One of the great difficulties in the way of an intimate knowledge of the relations of plants to soils lies in our ignorance of the laws of assimilation in the plant. The conditions under which the chemist studies these are of necessity artificial. He cannot be assured that he has even measurably reproduced the conditions of nature, and hence cannot be sure that similar results will be attained under such most natural conditions. Those most complex and peculiar changes which occur in chemical compounds under what, for want of a better term, are deno minated "vital forces" can never, at least under the pres ent limitations of knowledge, be fully uuderstood. And right here is the gist of the whole matter. A knowledge of the chemical constitution of a soil must precede a study of its relations to the full or incomplete, as the case may be, development of a plant dependent on it for nourishment. In other words, the constitution of a soil is a determinable quantity, the life-processes of the plant constitute an indeterminate quantity, and the relation of the two is the thing sought. No amount of chemical experimentation can bring into view the unknown factor.

The various experiment stations which are now estab. lished in every State in the Union can do much toward clearing away a great cloud of agricultural superstition relative to these subjects. There should be place for the theoretical as well as the practical in their work. It sinould be clearly shown that the constitution of a soil has far more to do with the growth of a crop of corn than the moon, or than any other of the oft-quoted and still entertained notions of strange and hidden forces. Tall oaks do not grow from little acorns except under the most favorable conditions of soil, and the conditions, again, are affected by the innumerable changes which occur in temperature, moisture or other variables, which render more or less tractable the various compounds on which the plant must feed.

The chemist who studies a soil does so by the same methods as those by which he would examine an unknown mineral, and usually with no greater care. He wishes, simply, to know what elements may occur in it, under what conditions, in what abundance, to what degree they may be dissociated, and whether there be present any substance which would interfere with their assimilation by the plant. In this way he arrives at a fair knowledge of the sample, but he can tell you little of its value for agricultural purposes. He here depends not on his knowledge of soil constitution or of its genesis, but on the facts of observation, which are familiar to ezery farmer, and which he unconsciously connects as cause and effect. It does not need a chemist to tell an observant farmer that he will not be likely to reap a strong growth of wheat from a sandbar. He has had as an instructor an experience in the relations of crops to the labor expended on them that led him to definite and valuable conclusions on this matter. But there are innumerable questions which he may put to the chemist and hope for a profitable answer. When once the soil has been exhausted of a necessary constituent he may learn from experience that this or that material judiciously applied will remedy the defect. The farmer, moreover, has yet to learn that, even in Iowa, there cannot be a constant draft on a soil and the same crop be produced with equal value each year for an indeterminate number of years. Each crop lessens the productive power of a soil by the amount of material which it removes from the soil each season. Here it is possible for the chemist to aid the producer by telling him exactly what has been taken from the soil, and thus indirectly telling him what is needed in the compost he may apply. This borders on organic chemistry and does not at present concern us.

Among the substances which must be present in a soil to give it an average degree of fertility stands pre-eminent the compound known as phosphoric acid. But this substance does not exist in the soil except in combination with some other substances, known technically as bases. These sub. stances are commonly, if not always, iron and alumina, with which they are in such chemical combination as to form salts known as phosphates. It is, however, not sufficient to know that these compounds are present. We must further know whether they are so associated with other compounds as to be readily disintegrated and rendered soluble, for unless soluble they cannot be used as plant-food. Now, neither of these compounds of phosphoric acid - i.e., iron and alumina phosphates - is available in that form. Experiment has shown that the form in which these substances are available is that of calcium (lime) phosphate. That this has a relation to the amount of calcium silicate in the soil is clearly proven, and that by a process of double decomposition of the three compounds the available one is obtained is also well known. But this process has not yet been certainly traced in nature. As stated at the beginning, it is right here that the processes of the laboratory and those of nature need to be connected. Whether they ever will be depends upon the support given to the great army of practical chemists whose attention is now directed to the theoretical features of agricultural chemistry.

It should be a matter of congratulation to the farmers of Iowa that work along these lines is now progressing very favorably at the experiment station at Ames. A vast amount of valuable information may be expected from this source, and in due course of time it will come.

\section{CURREN'T NOTES ON ANTHROPOLOGY. - X. \\ [Edited by D. G. Brinton, M.D., LL.D.] \\ The Ancient Libyan Alphabet.}

IN Science, May 8, I called attention to the new light thrown upon the history of our alphabet in its ancient form by the researches of Dr. Glaser among the ruined cities of Arabia. Another curious study in the same line is that offered by the Libyan alphabet. It appears to have been in common use among the Berber tribes of North Africa long before the foundation of Carthage, and is still employed constantly by the wild Touaregs of the Sahara. It is not the same as the Iberic alphabet of Spain, and in its forms is almost entirely independent of the Phœnician letters. It is composed of consonants, called tifinar, and vowel-points, known as tiddebakin. The latter are simple dots, the former are the lines of a rectangle, more or less complete. Several of them are found in the oldest Etruscan inscriptions, and on that known as the "inscription of Lemnos." Sepulchral epitaphs in this alphabet have been discovered dating two or perhaps three centuries before the Christian era; while rock-inscriptions of perhaps more ancient date, showing extremely archaic forms of the letters; have been copied from localities in the southern Atlas ranges.

The writers who have given especial attention to this littleknown subject are Faidherbe, Duveyrier, Halevy, Bissuel, and, recently, Dr. Collignon, who has a brief summary of results in a late issue of Les Sciences Biologiques.

\section{The Aborigines of Asia Minor.}

The artistic and linguistic studies into the proto-ethnology of Asia Minor (see Science, May 20) are happily supplemented 